\title{
Advanced membrano - proliferative glomerulonephritis in a 2-month-old Nigerian male infant: A case report
}

\author{
Ogoke C.C ${ }^{1}$, Okafor H. U², Uwaezuoke S.N², Ndu I.K ${ }^{3}$, Okafor O.C \\ 1. Department of Pediatrics, Federal Medical Centre, Owerri, Nigeria. 2.Department of Pediatrics, University of Nigeria \\ Teaching Hospital, Ituku-Ozalla, Enugu, Nigeria. 3. Department of Pediatrics, Enugu State University Teaching Hospital, \\ Enugu, Nigeria. 4. Department of Pathology, University of Nigeria Teaching Hospital, Ituku-Ozalla, Enugu, Nigeria
}

Correspondence: Uwaezuoke S.N. Address: Department of Pediatrics, UNTH, Ituku-Ozalla, Enugu, Nigeria. Email: snuwaezuoke@yahoo.com

Received: August 19, 2015

DOI : $10.5430 /$ crim.v2n4p42
Accepted: September 27, 2015

URL: http://dx.doi.org/10.5430/crim.v2n4p42

\section{Abstract}

Introduction: Membrano-proliferative glomerulonephritis (MPGN) is rare in infancy and remains an uncommon cause of chronic nephritis which primarily affects children and young adults.

Case presentation: The index case is a 2-month-old male infant who presented with vomiting, generalized body swelling and anuria following ingestion of some parent-prescribed drugs. Following mortality on the 28th day of admission, a post-mortem evaluation revealed an advanced MPGN: a histological picture best described as "a 2-month-old with the kidneys of a 70-year-old”.

Conclusion: The case report aims to underscore the possibility of MPGN in early infancy albeit rare. It also highlights the need for a high index of suspicion in cases of unexplained acute renal failure especially in settings where there are limited facilities for diagnosis.

\section{Keywords}

Membrano-proliferative glomerulonephritis, Acute renal failure, Infancy

\section{Introduction}

Membranoproliferative glomerulonephritis (MPGN) is an uncommon cause of chronic nephritis which occurs primarily in children and young adults ${ }^{[1-3]}$. MPGN refers to a pattern of glomerular injury based on characteristic histopathologic findings which include proliferation of mesangial and endothelial cells and expansion of the mesangial matrix, thickening of the peripheral capillary walls by sub-endothelial immune deposits and/or intra-membranous dense deposits and mesangial interposition into the capillary wall, giving rise to a "double-contour" or "tram-track" appearance on light-microscopy ${ }^{[1]}$.

MPGN can be subdivided into idiopathic and secondary types. The secondary types are more common than the idiopathic types. Idiopathic MPGN is subdivided into types I, II and III based on ultra-structural appearance ${ }^{[1]}$. Although the light microscopic features of the 3 types are indistinguishable, MPGN type I is characterized by sub-endothelial deposits, type 
II by dense deposits in the glomerular basement membrane (dense deposit disease), and type III by sub-epithelial and sub-endothelial deposits.

However, an alternative classification system was later proposed based on pathogenetic mechanism: immune complex-mediated MPGN, complement-mediated MPGN and mechanisms unrelated to immunoglobulin or complement deposition ${ }^{[4]}$. Clinical presentation is similar among the 3 idiopathic types but they manifest somewhat different mechanisms of complement activation ${ }^{[5]}$. Recently, an improved understanding of the role of complement in the pathogenesis of MPGN has resulted in a proposed re-classification into immunoglobulin-mediated disease (driven by the classical complement pathway) and non-immunoglobulin-mediated disease (driven by the alternative complement pathway) ${ }^{[6]}$.

Majority of patients with MPGN present with nephrotic syndrome; others may manifest with asymptomatic microscopic hematuria and proteinuria but rarely with acute or rapidly progressive renal failure ${ }^{[1,3]}$. Most cases of MPGN type II in fact progress to end-stage kidney disease ${ }^{[7]}$. Although there are isolated reports of MPGN in a 15-month-old male toddler ${ }^{[8]}$ and on an 8-month-infant ${ }^{[9]}$, to the best of our knowledge there are no reports in patients as early as 2 months of life.

\section{Case presentation}

Baby R.C, a 2-month-old male infant, presented to the University of Nigeria Teaching Hospital (UNTH), Enugu on 2nd September, 2009 through the Children Emergency ward with complaints of complete cessation of urine output for two weeks, generalized body swelling for one week and vomiting for three days all prior to presentation. The anuria was sudden in onset and followed ingestion of some parent-prescribed drugs for treatment of a febrile illness. These drugs included paracetamol, dihydroartemisinin/piperaquine and cotrimoxazole (with unregistered brand names). There was no history of abnormal urine stream, dysuria or gross hematuria and no family history of renal disease.

Initial examination on admission revealed an acutely ill infant who had tachypnea (respiratory rate $=52$ breaths/minute) and tachycardia (heart rate $=128 / \mathrm{min}$ ); was pale with generalized edema; afebrile; and anicteric. The liver was palpable by $4 \mathrm{~cm}$ below the right costal margin but was not tender. Blood pressure could not be measured because there was no appropriate-sized cuff. Urgent serum electrolyte, urea and creatinine estimation showed azotemia (sodium $=136 \mathrm{mmol} / \mathrm{L}$, potassium $=5 \mathrm{mmol} / \mathrm{L}$, bicarbonate $=19 \mathrm{mmol} / \mathrm{L}$, chloride $=88 \mathrm{mmol} / \mathrm{L}$, urea $=11.4 \mathrm{mmol} / \mathrm{L}$ and creatinine $=$ $688 \mathrm{mmol} / \mathrm{L}$ ). Patient was also glucose-6-phosphate dehydrogenase (G-6-PD) deficient. Urinalysis could not be done because the patient was anuric. The admitting diagnosis was intrinsic acute renal failure (ARF) possibly secondary to toxic nephropathy (based on the history of self-advised medications). Urgent intermittent peritoneal dialysis (PD) was commenced with hypertonic dialysate. Patient was transfused once during the period of hospitalization. Dialysis effluent for the first 24 hours was hemorrhagic but gradually became clear. Urine bag was however was empty. PD was continued but was erratic due to recurrent catheter blockage and leakage which necessitated frequent manipulation. A repeat abdominal ultrasound reported 'features suggestive of chronic nephropathy' even though a previous ultrasound noted normal kidneys. By the 13th day of admission, the child was still anuric and daily intravenous furosemide at $1 \mathrm{mg} / \mathrm{kg} / \mathrm{d}$ was commenced. Serial serum electrolyte, urea and creatinine results showed normal sodium and potassium, persistent metabolic acidosis and azotemia. However, by the 14th day of admission, patient had a wound dehiscence with partial evisceration of gut following infection of the peritoneal catheter insertion site. By then, patient had undergone 26 sessions of PD. He died on the 28th day of admission despite intervention measures like intravenous antibiotics for iatrogenic infections and surgical repair. Post-mortem evaluation revealed normal gross findings in both kidneys (see Figure 1) and histopathological findings consistent with an advanced MPGN (see Figures 2 and 3). Other concomitant findings included neutrophilic exudate in glomeruli; and ischaemic acute tubular necrosis. A comprehensive investigation including serology tests (such as C3, Hepatitis B/C and HIV serology) could not be done because of the initial diagnosis of ARF secondary to toxic nephropathy. 


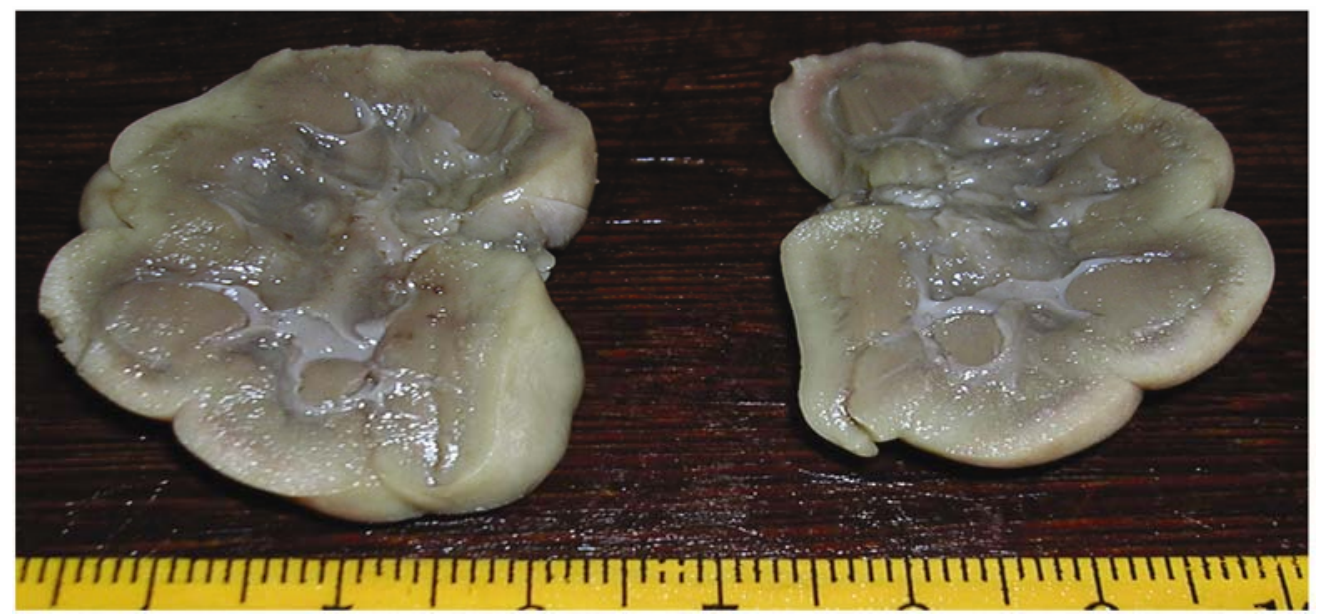

Figure 1. Section of the right kidney without any remarkable finding

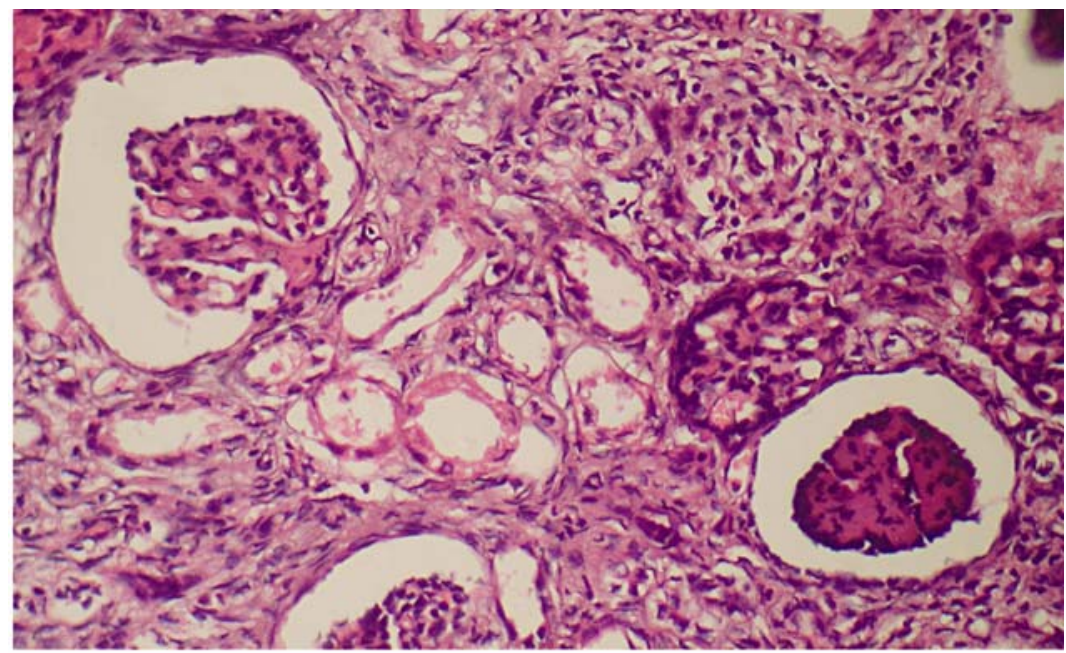

Figure 2. (HE, $\times 200$ ). The glomerulus on the upper left corner shows prominent hypercellularity with mesangial matrix expansion and prominent lobular pattern. The glomerulus on the lower right corner shows very advanced sclerosis.

\section{Discussion}

This index case of advanced MPGN in a 2-month-old infant is the first reported case from our center. A previous report from this center was a male adolescent who presented pre-mortem with features of acute renal failure and lobar pneumonia; post-mortem examination revealed a solitary kidney with MPGN as the fundamental disease ${ }^{[10]}$.

MPGN actually represents a pattern of injury seen on light microscopy. Recent advances in understanding of the underlying pathology have led to a proposed classification scheme based on immunofluorescence findings. Dysregulation of the complement system has been identified as a major risk factor for the development of an MPGN pattern of injury on renal biopsy ${ }^{[11]}$. MPGN accounts for approximately 7\%-10\% of all cases of biopsy-confirmed GN seen in developed countries ${ }^{[12,13]}$. However, in developing countries such as Nigeria and Turkey, MPGN was found to be the predominant histological lesion seen in childhood nephrotic syndrome ${ }^{[14,15]}$.

The initial presentation with features suggestive of ARF in our patient did not raise our index of suspicion for MPGN especially with the antecedent history of ingestion of parent-prescribed unregistered brand of drugs. We therefore thought the patient had ARF due to toxic nephropathy. 
Figure 3. (HE, $\times 600)$. The glomerulus shows prominent hypercellularity with mesangial matrix expansion and diffuse thickening of the glomerular basement membrane

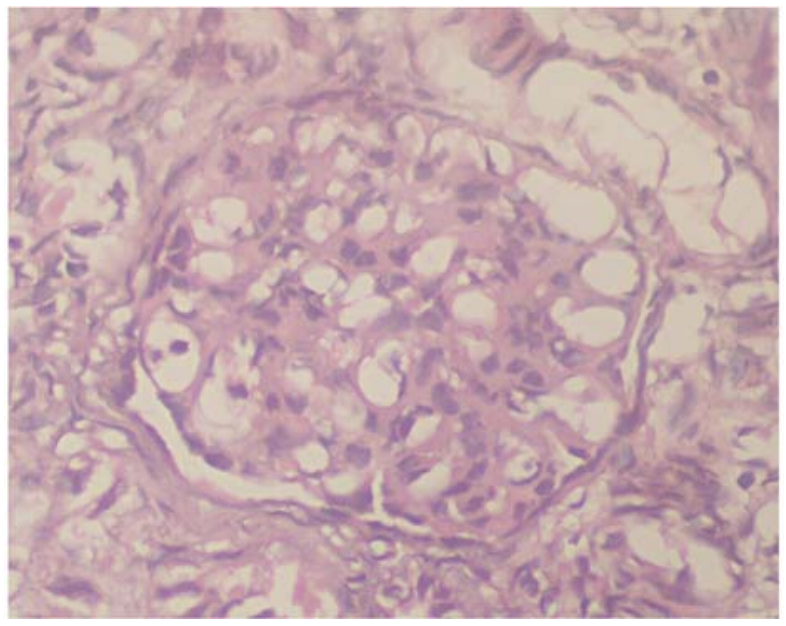

The pathogenesis of MPGN is not clearly understood until the recent re-classification which highlighted the role of complement in its pathogenesis ${ }^{[6]}$. In a recent review ${ }^{[16]}$, it is now recognized that many cases of MPGN show only deposition of the complement component-C3 due to dysregulation of the alternate pathway of complement activation; these cases are currently classified as C3 glomerulopathies even though not all cases show an MPGN pattern. Based on the previous classification, MPGN type I is believed to result from chronic antigenemia and generation of nephritogenic immune complexes which selectively localize to the sub-endothelial spaces ${ }^{[17]}$. We believe the diagnosis of MPGN was missed pre-mortem because of its rare presentation in the patient's age bracket, and as acute renal failure. Generally, patients with MPGN may present in one of the following four ways: nephrotic syndrome (40\%-70\%), acute nephritic syndrome (20\%-30\%), asymptomatic proteinuria and hematuria detected on routine urinalysis (20\%-30\%), and recurrent episodes of gross hematuria $(10 \%-20 \%)^{[17]}$.

Our patient could have presented as acute nephritic syndrome, but the diagnostic flaw was our inability to measure the blood pressure due to non-availability of diagnostic tool. In addition, a basic urinalysis to detect possible proteinuria or hematuria was not done because the patient remained anuric throughout the period of admission. In retrospect, the presentation of the patient fitted into the picture of MPGN; renal dysfunction occurs in more than 50\% of patients and the incidence of anemia is commonly out of proportion to the degree of renal failure ${ }^{\text {[17] }}$. Again, our patient had abnormal renal function test, was remarkably pale on presentation, and required blood transfusion during hospitalization. The anemia seen in such patients is thought to be related to complement-mediated hemolysis ${ }^{[17]}$.

Finally, the absence of adequate facilities for diagnostic evaluation particularly immuno-fluorescent and electron microscopy did not allow for a sub-classification of MPGN as the sub-types cannot be differentiated on light microscopy. Since the diagnosis of MPGN was made post-mortem, it was not possible to establish if it was the secondary type which would have required relevant serology tests such as hepatitis B/C and HIV serology. In children, MPGN is frequently idiopathic whereas in adults it is secondary and is commonly associated with cryoglobulinemia and hepatitis $\mathrm{C}$ virus infection ${ }^{[17]}$.

\section{Conclusion}

The case report has documented the possibility of MPGN in early infancy albeit rare. It also highlights the need for a high index of suspicion in cases of unexplained acute renal failure especially in settings where there are limited facilities for diagnosis. 


\section{Limitations}

Renal biopsy was not done pre-mortem because the index patient was ill-looking and remained on peritoneal dialysis throughout the period of hospitalization. Basic urinalysis could not be done because of anuria which persisted till mortality.

\section{References}

[1] Ira DD, Ellis DA. Membrano proliferative glomerulonephritis. In: Behrman, KJ(Ed). Nelson Textbook of Pediatrics. Saunders. 2004; 17: 1742-1743.

[2] Arslan S, Saatchi U, Ozen S, et al. Membrano proliferative glomerulonephritis in childhood: factors affecting prognosis. Int Urol Nephrol. 1997; 29: 711-716. PMid:9477371 http://dx.doi.org/10.1007/BF02552190

[3] McEnery PT. Membranoproliferative glomerulonephritis: The Cincinnati experience-cumulative renal survival from 1957 to 1989. J Pediatr. 1990; 116: S109. http://dx.doi.org/10.1016/S0022-3476(05)82712-X

[4] Sethi S, Fervenza FC. Membranoproliferative glomerulonephritis-a new look at an old entity. N Eng J Med. 2012; 366(12): 1119-1131. PMid:22435371 http://dx.doi.org/10.1056/NEJMra1108178

[5] Lorenz EC, Sethi S, Leung N, et al. Recurrent membranoproliferative glomerulonephritis after kidney transplantation. Kidney Int. 2010; 77(8): 721-728. PMid:20130531 http://dx.doi.org/10.1038/ki.2010.1

[6] Bomback AS, Appel GB. Pathogenesis of the C3 glomerulopathies and reclassification of membranoproliferative glomerulonephritis. Nature Rev Nephrol. 2012; 8: 634-642. PMid:23026947 http://dx.doi.org/10.1038/nrneph.2012.213

[7] West CD. Membranoproliferative hypocomplementemic glomerulonephritis. Nephron. 1973; 10: 134. http://dx.doi.org/10.1159/000180226

[8] James S, Neiberger R, Donelly W, et al. Membrano proliferative Glomerulonephritis in a fifteen-month-old boy. Child Nephrol Urol. 1990; 10: 218-221. PMid:2088595

[9] Kari JA, Bamashmous H, Lingawi S, et al. Infantile nephritic syndrome and congenital glaucoma. Pediatr Nephrol. 2001; 1: 894-897. http://dx.doi.org/10.1007/s004670100669

[10] Okafor HU, Uwaezuoke SN, Okafor OC. Membranoproliferative glomerulonephritis in a Nigerian adolescent with congenital solitary kidney: unraveling the cause of mortality. J Coll Med. 2009; 14(2): 85-88

[11] Masani N, Jhaveri KD, Fishbane S. Update on Membranoproliferative glomerulonephritis. Clin J Am Soc Nephrol. 2014; 9(3): 600-608. PMid:24408117 http://dx.doi.org/10.2215/CJN.06410613

[12] Swaminatha S, Leung N, Lager DJ, et al. Changing incidence of glomerular disease in Olmsted County, Minnesota: a 30-year renal biopsy study. Clin J Am Soc Nephrol. 2006; 1(3): 483-7.

[13] Briganti EM, Dowling J, Finlay M, et al. The incidence of biopsy-proven glomerulonephritis in Australia. Nephrol Dial Transplant. 2001; 16(7): 1364-1367. PMid:11427626 http://dx.doi.org/10.1093/ndt/16.7.1364

[14] Asinobi AO, Gbadegesin RA, Adeyemo AA, et al. The predominance of membranoproliferative glomerulonephritis in childhood nephrotic syndrome in Ibadan, Nigeria. West Afr J Med. 1999; 18(3): 203-206. PMid:10593158

[15] Ozkaya N, Çakar N, Ekim M, et al. Primary nephrotic syndrome during childhood in Turkey. Pediatr Int. 2004; 46(4): 436-438. PMid:15310309 http://dx.doi.org/10.1111/j.1442-200x.2004.01920.x

[16] Cooke HT, Pickering MC. Histopathology of MPGN and C3 glomerulopathies. Nat Rev Nephrol. 2015; 11(1): 14-22. PMid:25447133 http://dx.doi.org/10.1038/nrneph.2014.217

[17] Alchi B, Jayne D. Membranoproliferative glomerulonephritis. Pediatr Nephrol. 2010; 25(8): 1409-1418. PMid:19908070 http://dx.doi.org/10.1007/s00467-009-1322-7 